\title{
Iniciação à docência e desenvolvimento de ações de suporte ao ensino de matemática: subprojeto PIBID/CPPP/Matemática
}

\section{Teaching initiation and development of actions to support the teaching of mathematics: subproject PIBID/CPPP/Mathematics}

DOI: $10.46814 / \operatorname{lajdv} 3 n 1-023$

Recebimento dos originais: 30/10/2020

Aceitação para publicação: 23/12/2020

\section{Geovane Soares Balejo}

Licenciatura em Matemática - Universidade Federal de Mato Grosso do Sul (UFMS) - Câmpus de Ponta Porã (CPPP)

Instituição de Atuação atual: Polícia Militar do Estado de Mato Grosso do Sul

Endereço: Rua Tamarindeiro, 219 - Ponta Porã/MS

E-mail: geovane.balejo@ hotmail.com

\section{José Ramão de Souza Chiquitin}

Especialização em Gestão Escolar - Universidade Federal de Mato Grosso do Sul (UFMS) - Campo Grande/MS (CPPP)

Instituição de Atuação atual: SED - Secretária de Estado de Educação de Mato Grosso do Sul Endereço: Rua Paraguai, 292 - Centro - Ponta Porã/MS

E-mail: jose_ramao@hotmail.com

\section{Caroline da Silva Oliveira}

Graduação em Licenciatura em Matemática - Universidade Federal de Mato Grosso do Sul (UFMS)

- Câmpus de Ponta Porã (CPPP)

Instituição de Atuação atual: Contábil Facont

Endereço: Rua Cuiabá, 3155 - Dourados/MS

E-mail: caroline_oliveira93@hotmail.com

\section{Vanilda Alves da Silva}

Doutorado em Educação pela Universidade Católica Dom Bosco (UCDB) - Campo Grande/MS Instituição de Atuação atual: Universidade Federal de Mato Grosso do Sul (UFMS) - Câmpus de Ponta Porã (CPPP)

Endereço: Rua Cider Cersózimo de Souza, 1820, apto 22 - Residencial Moriá 2 - Vila Aurora Dourados/MS

E-mail: vanilda.ufms.pp@gmail.com

\section{RESUMO}

O subprojeto PIBID/CPPP/Matemática tem por objetivo a iniciação à docência dos acadêmicos do curso de licenciatura em Matemática da Universidade Federal de Mato Grosso do Sul - UFMS, em um ambiente bem orientado, com vivência de várias técnicas de ensino e seus efeitos, promovendo a melhoria da qualidade da educação e a integração de acadêmicos da universidade federal com as escolas públicas. O Projeto foi desenvolvido na Escola Estadual João Brembatti Calvoso, e encontrou como dificuldade maior a aprendizagem de conteúdos matemáticos, uma vez que os alunos não conseguem articular o abstrato com a prática e sua aplicabilidade. A Matemática ensinada na sala de aula nem sempre é suficiente para mostrar o quanto ela é interessante, necessária e ambientada no nosso espaço cultural, devido à realidade enfrentada pelos professores, em suas vivências de sala de aula: 
sala superlotada e uma lista enorme de conteúdos a serem ministrados. Os professores da escola alvo do Projeto solicitaram, aos acadêmicos participantes, a contribuição com novos recursos para apresentar a matemática de forma menos teórica e desinteressante ao estudante, permitindo a compreensão de conteúdos, até então vistos por eles como desnecessários ao seu aprendizado. Desse modo, pesquisamos, elaboramos e desenvolvemos atividades lúdicas como os jogos, envolvendo a Matemática e o desenvolvimento do raciocínio lógico. A partir desses recursos pudemos observar resultados satisfatórios quanto ao desempenho na disciplina, melhor rendimento escolar, não só na disciplina de matemática, mas, sobretudo, no contexto interdisciplinar. Por meio dessas atividades foi possível demonstrar o quanto a Matemática é interessante e importante para o desenvolvimento de uma sociedade e, principalmente, do indivíduo/cidadão que nela se insere.

Palavras-chave: Iniciação à docência, Jogos matemáticos, Ensino da Matemática.

\begin{abstract}
The subproject PIBID/CPPP/Mathematics aims to initiate the teaching of academics of the degree course in Mathematics of the Federal University of Mato Grosso do Sul - UFMS, in a well oriented environment, with experience of various teaching techniques and their effects, promoting the improvement of the quality of education and the integration of academics from the federal university with public schools. The Project was developed at the João Brembatti Calvoso State School, and found it more difficult to learn mathematical content, since students cannot articulate the abstract with practice and its applicability. The mathematics taught in the classroom is not always enough to show how interesting it is, necessary and set in our cultural space, due to the reality faced by teachers in their classroom experiences: an overcrowded classroom and a huge list of contents to be taught. The teachers of the target school of the Project asked the participating academics to contribute with new resources to present mathematics in a less theoretical and uninteresting way to the student, allowing the understanding of contents, until then seen by them as unnecessary to their learning. In this way, we research, elaborate and develop playful activities such as games, involving Mathematics and the development of logical reasoning. From these resources we were able to observe satisfactory results regarding performance in the discipline, better school performance, not only in the discipline of mathematics, but above all, in the interdisciplinary context. Through these activities it was possible to demonstrate how interesting and important Mathematics is for the development of a society and, especially, for the individual/citizen who is part of it.
\end{abstract}

Keywords: Initiation to teaching, Mathematical games, Teaching of Mathematics.

\title{
1 INTRODUÇÃO
}

O Subprojeto de Matemática do Programa Institucional de Bolsas de Iniciação á Docência (PIBID) da Fundação Universidade Federal de Mato Grosso do SUL (UFMS) do Campus de Ponta Porã/MS (CPPP) iniciou-se no ano letivo de 2010, na Escola Estadual João Brembatti Calvoso. O grupo dos participantes é composto por dez acadêmicos bolsistas, um professor supervisor que atua na escola em sala de aula e uma coordenadora docente da UFMS/CPPP.

O Subprojeto de Matemática PIBID/CPPP/UFMS surgiu com a finalidade de possibilitar a vivência e experiência docente e de contribuir para a construção do conhecimento na formação de futuros educadores. Além disso, o projeto objetiva favorecer a aquisição de metodologias e práticas 
docentes que orientem e ajudem os alunos a verem, nos problemas vivenciados no processo de aprendizagem da matemática, uma forma de ler o mundo que os cerca e valorizar o espaço da escola pública como um lugar de aprendizado.

No período de atuação do grupo, todos os bolsistas puderam vivenciar, na prática, a utilização das metodologias e atividades docentes adquiridas nas disciplinas pedagógicas do curso de licenciatura em Matemática.

Durante o desenvolvimento do subprojeto na escola, foi surpreendente perceber que as atividades ligadas à Matemática, na maioria das vezes, se restringiam apenas ao uso do livro didático. Esse fato se deve, possivelmente, devido à realidade encontrada como a carga horária excessiva, dos professores de Matemática (Ponta Porã/MS necessita de profissionais nessa área), a lista de conteúdos a serem trabalhados e a quantidade de alunos em sala de aula. Diante desses fatos evidenciados, utilizamos novas tendências do ensino da Matemática, mais eficazes, de modo que os alunos possam desenvolver o raciocínio lógico e assimilar conteúdos matemáticos.

A Matemática ensinada na sala de aula nem sempre é suficiente para mostrar o quanto essa ciência é interessante, necessária e ambientada no nosso espaço cultural, devido à realidade enfrentada pelos professores, como sala superlotada, além de uma lista enorme de conteúdos a serem ministrados. Nesse sentido os professores solicitaram uma contribuição, aos Pibidianos, por meio de planejamento de aula que disponibilizem novos recursos para apresentação uma aula interessante.

Com o objetivo de auxiliar alunos a pensar de forma independente, e permitir a formação de indivíduos capazes de perceber a Matemática à sua volta, os acadêmicos bolsistas do subprojeto, com o apoio da supervisão da escola, realizaram pesquisas para buscar materiais concretos e atividades lúdicas. Em seguida, chegou o momento de colocar em prática essas novas atividades pedagógicas, como desafios e jogos que podem permitir resultados satisfatórios, os quais serão apresentados mais adiante.

\section{REFERENCIAL TEÓRICO}

A iniciação à docência tem se revelado uma importante etapa no processo de formação do licenciando, tornando-se objeto de estudo e tendo como foco principal a figura do professor. Esses estudos relacionam-se ao processo de aprender a ensinar, utilizando a prática como um espaço de reflexão e conhecimento, garantindo ao futuro professor o domínio daquilo com que irá trabalhar.

Imbernón afirma que "a formação inicial, como tem ocorrido, não oferece preparo suficiente para aplicar uma nova metodologia, nem para aplicar métodos desenvolvidos teoricamente em sala de aula" (2000, p.41). 
Segundo Garcia (1995), o conhecimento do professor envolve diferentes categorias: conhecimento do conteúdo; conhecimento pedagógico geral; conhecimento do currículo, materiais e programas; conhecimento pedagógico dos conteúdos; conhecimento do aluno e das suas características; conhecimento do contexto educativo; conhecimento dos fins, propósitos e valores educativos.

A partir daí surgem dúvidas quanto às suas possibilidades de ação, sobre metodologia, domínio do conteúdo, a articulação de teoria e prática e as condições de trabalho. Cabe, então, à formação inicial proporcionar ao futuro educador oportunidades de prática, pois, como define Perrenoud (1993, p.57), “o ensino é uma prática relacional complexa onde o professor muitas vezes se defronta com o imprevisível e deve tomar decisões rápidas”. Por essas razões, a experiência de iniciação à docência se torna uma etapa de fundamental importância na carreira profissional do professor, pois o leva a conhecer a realidade que o espera, devendo, então, ser contínua durante todo o curso de licenciatura.

Sabemos que a iniciação à docência, mais do que um processo, é a oportunidade de o futuro professor se inserir nas realidades escolares e vivenciar as mais diversas situações que os educadores enfrentam. Nesse contexto, no Projeto, damos ênfase em três pontos que são de extrema importância na educação: o saber dosar a relação teoria/prática; criar possibilidades para o aluno produzir ou construir conhecimentos, em lugar de apenas transferi-los e o ato de reconhecer que, ao ensinar, se está aprendendo.

Ao iniciar a docência, mesmo ainda em fase de formação universitária, esses três pontos devem fazer parte da educação a fim de torná-la eficaz. Freire (2003) ressalta que há necessidade de uma reflexão crítica sobre a prática educativa. Não havendo essa reflexão, a teoria pode se tornar apenas discurso e, dessa forma, a prática não passa de ativismo e uma reprodução alienada.

Esse embasamento proporciona conhecimento ao acadêmico, que poderá utilizar de metodologias que auxiliem no ensino da Matemática, entre elas os jogos. Como se sabe, o jogo não se resume ao simples fato de jogar, mas propicia o desenvolvimento do raciocínio lógico-matemático, o desenvolvimento intelectual, a interação, o confronto entre diferentes formas de pensar, a formulação de estratégias e por fim a construção do saber. O jogo permite, ainda, ao aluno, experimentar características sociais e culturais, provocando a descontração, a aquisição de regras, a expressão do imaginário e a apropriação de conhecimentos. A atividade lúdica é, essencialmente, um grande laboratório em que ocorrem experiências inteligentes e reflexivas, experiências essas que produzem conhecimento.

Segundo os PCN: 
Por meio de jogos as crianças não apenas vivenciam situações que se repetem, mas aprendem a lidar com símbolos e a pensar por analogia (jogos simbólicos), os significados das coisas passam a ser imaginados por elas. Ao criarem essas analogias, tornam-se produtoras de linguagens, criadoras de convenções, capacitando-se para se submeterem a regras e dar explicações. (BRASIL, 1997, p.48)

Dessa forma, verificamos que o jogo deixa de ser apenas uma brincadeira e torna-se uma ferramenta de real importância no desenvolvimento humano e auxiliadora de aprendizagem.

Conforme BITTAR \& FREITAS (2005) [...] “O jogo em sala de aula pode ser eficaz para aumentar a concentração e a atividade mental e assim contribuir para o envolvimento das crianças em atividades matemáticas. " [...].

Nesse sentido os jogos permitem fazer o papel de facilitador na aprendizagem de conteúdos matemáticos.

No entanto é relevante que o professor faca papel de mediador, além disso deve planejar com qualidade as atividades que irá propor para seus alunos para que obtenha resultados satisfatórios. Assim, torna-se necessário que o professor utilize metodologias diferenciadas e tornando sua aula prazerosa, despertando a participação, entusiasmo e interesse de seus alunos, uma vez que ao usar formas diferenciadas de ensino, a aprendizagem torna-se significativa.

Vale ressaltar que o professor deverá elaborar tais atividades deixando claro e mostrando o objetivo da aula planejada para seus alunos. No entanto, importante tomar cuidado para que o lúdico tenha o seu papel no ensino.

Como podemos perceber na afirmação de Bittar e Freitas (2005) "Muitas vezes, esses materiais assumem o lugar principal no ensino e não cumprem sua função que é a de permitir que o aluno, através de manipulações do material, construa seu conhecimento.

Portanto, o professor deve estar atento para que não se perca o objetivo da utilização do lúdico.

DAVIS \& OLIVEIRA afirmam que,

A motivação para aprender nada mais é do que o reconhecimento, pelo indivíduo, de que conhecer algo irá satisfazer suas necessidades atuais e futuras. [...] uma pessoa motivada para aprender constrói o conhecimento mais prontamente do que uma sem motivação. (DAVIS \& OLIVEIRA, 1993. p.84 e 85).

Vale lembrar ainda que esse tipo de atividade oportuniza os alunos a manipulação de materiais lúdicos, estimulando e motivando o processo ensino e aprendizagem e o aluno quando se sente motivado desenvolve seu raciocínio lógico contruindo seu próprio conhecimento.

Ainda, segundo os PCN:

Por meio de jogos as crianças não apenas vivenciam situações que se repetem, mas aprendem a lidar com símbolos e a pensar por analogia (jogos simbólicos), os significados das coisas 
passam a ser imaginados por elas. Ao criarem essas analogias, tornam-se produtoras de linguagens, criadoras de convenções, capacitando-se para se submeterem a regras e dar explicações. (BRASIL, 1997, p.48)

Dessa forma, verificamos que o jogo deixa de ser apenas uma brincadeira e torna-se uma ferramenta de real importância no desenvolvimento humano e auxiliadora de aprendizagem.

Moura (1991) nos diz que o jogo aproxima-se da Matemática via desenvolvimento de habilidades de resoluções de problemas. Então, acreditamos que a utilização de jogos articulado com os conteúdos matemáticos poderá facilitar o aprendizado dos alunos.

\section{ATIVIDADES DESENVOLVIDAS}

Entre as atividades e ações realizadas pelo Subprojeto de Matemática PIBID/CPPP/UFMS destacam-se a participação e acompanhamento nas aulas de Matemática na escola parceira; Oficinas de Jogos; Treinamento para OBMEP; e outras ações apresentadas no quadro a seguir:

\begin{tabular}{|c|c|}
\hline Ações & Resumo \\
\hline Treinamento para a OBMEP & $\begin{array}{l}\text { Os Pibidianos utilizavam-se dos bancos de dados da OBMEP, vídeos } \\
\text { e atividades complementares auxiliando os alunos na interpretação de } \\
\text { enunciados dos problemas e em suas resoluções. }\end{array}$ \\
\hline Oficina de jogos & $\begin{array}{l}\text { O supervisor do projeto reuniu-se com os professores de Matemática } \\
\text { da escola que indicaram os principais conteúdos que os alunos tinham } \\
\text { dificuldades. Os Acadêmicos bolsistas juntamente com a } \\
\text { Coordenadora do PIBID pesquisaram, elaboraram e estudaram } \\
\text { atividades (Sequência Didática) para auxiliar o aprendizado destes } \\
\text { conteúdos, que foram desenvolvidas em oficinas no contra-turno. Os } \\
\text { alunos foram selecionados por professores, coordenadores da escola } \\
\text { para participarem das oficinas. Vale ressaltar ainda que esse material } \\
\text { foi utilizado com outras turmas de outros anos que tinham a mesma } \\
\text { dificuldade. }\end{array}$ \\
\hline Acompanhamento em sala de aula & $\begin{array}{l}\text { Os bolsistas auxiliavam os professores de Matemática durante as } \\
\text { aulas, atendiam os alunos individualmente em suas carteiras tirando } \\
\text { dúvidas e ajudando no desenvolvimento das atividades propostas. }\end{array}$ \\
\hline Aperfeiçoamento em Matemática & $\begin{array}{l}\text { As aulas de aperfeiçoamento também aconteciam no contra-turno dos } \\
\text { alunos e tinha como objetivo auxiliar os alunos revisando os } \\
\text { conteúdos que seriam cobrados e avaliados nas provas mensais e } \\
\text { bimestrais. }\end{array}$ \\
\hline \multirow[t]{2}{*}{$\begin{array}{l}\text { Participação em Eventos com } \\
\text { apresentação de trabalhos }\end{array}$} & $\begin{array}{l}\text { - XI ENEM - Encontro Nacional de Educação Matemática - } \\
\text { Educação Matemática: Retrospectiva e Perspectiva - SBEM } \\
\text { Curitiba/PR. } \\
\text { - III Escola de Inverno de Educação Matemática e I Encontro } \\
\text { Nacional Pibid - Matemática - UFSM - Santa Maria/RS. } \\
\text { - X EGEM- Encontro Gaúcho de Educação Matemática - } \\
\text { UNIVATES - Lajeado/RS. }\end{array}$ \\
\hline & $\begin{array}{l}\text { - II ENCOSMAT- Encontro Sul-mato-grossense de } \\
\text { Matemática - UEMS - Paranaíba/MS. }\end{array}$ \\
\hline
\end{tabular}


- XI ESEM- Encontro Sul-mato-grossense de Educação Matemática - UFMS - Nova Andradina/MS.

\section{RESULTADOS OBTIDOS}

Como futuros educadores é de relevância participar do Subprojeto de Matemática do PIBID/CPPP/UFMS, pois temos tido vários resultados gratificantes, entre eles, a experiência da docência, além de poder desenvolver na escola de ensino fundamental nosso conhecimento aprendido na universidade.

Proporcionando medidas significativas, avaliando cada ação, repensando cada uma delas (momento de reflexão), buscando a realização cada vez mais qualificada do nosso trabalho, pudemos perceber, por meio de relatos de professores e alunos envolvidos no projeto, dados e resultados que revelam aproveitamento dos alunos. Além disso, é importante ressaltar, como valor e importância dessa atividade, o marco criado por ela no período de realização.

A utilização de jogos mostrou-se importante para nossa metodologia, tendo em vista que, ao articularmos divertimento e aprendizagem, de fato, percebemos o favorecimento do aprendizado.

Com essa experiência pudemos perceber quanto os alunos da escola que participaram das oficinas foram auxiliados a romperem barreiras no aprendizado da Matemática, uma vez que, tal como pudemos perceber, passaram a ver a Matemática com menos medo e mais entusiasmo. Ao mesmo tempo em que aprendem Matemática, nós, os acadêmicos-pesquisadores, "aprendemos a ensinar" e adquirimos conhecimentos e experiências necessárias à docência.

Para nós, acadêmicos "Pibidianos", o projeto é de fato importante, tanto no aspecto do ensino, quanto no de aprendizado. Tivemos a oportunidade de vivenciar a docência no cotidiano escolar e colocar em prática conhecimentos adquiridos em sala de aula, bem como desenvolver competências previstas no Projeto Pedagógico do curso de Matemática, o que contribui significativamente na nossa formação. É nesse contexto que o Subprojeto de Matemática PIBID/CPPP/UFMS acontece. Os fatores já relatados contribuíram, certamente, para que nossas atividades tivessem êxito e, consequentemente, constituíram como papel facilitador no processo ensino e aprendizagem.

Consideramos, ao final desta experiência, que é de grande importância a inclusão do licenciando no contexto escolar, desde o início de sua formação, tanto para o acadêmico quanto para a escola. O contato entre os "pibidianos" com o professor supervisor do Subprojeto de Matemática PIBID/CPPP/UFMS e demais professores da escola propicia uma valiosa troca de experiências, já que os bolsistas, em constante momento de pesquisa, podem oferecer metodologias inovadoras, enquanto os professores podem compartilhar sobre suas experiências em sala de aula. Dessa forma, a parceria entre escola e universidade favorece o processo de desenvolvimento da educação do país. 


\section{REFERÊNCIAS BIBLIOGRÁFICAS}

BITTAR, M. e FREITAS, J. L. M de. Fundamentos e metodologia de Matemática para os ciclos iniciais do ensino fundamental. 2. ed. Campo Grande: UFMS, 2005.

BRASIL. Secretaria de Educação Fundamental. Parâmetros Curriculares Nacionais: Matemática / Secretaria de Educação Fundamental. Brasília: MEC / SEF, 1997.

DAVIS, C. e OLIVEIRA, Z de. Psicologia na Educação. 2 ed. São Paulo: Cortez, 1993.

FREIRE, P. Pedagogia da autonomia: saberes necessários à prática educativa. São Paulo: Paz e Terra, 2003.

IMBERNÓN, F. Formação docente e profissional: formar-se para a mudança e a incerteza. São Paulo: Cortez, 2000. (Coleção Questões da Nossa Época, v.77).

MARCELO GARCIA, C. El Pensamiento del professor. Barcelona: CEAC, 1987.

MOURA, M. O. de. A construção do signo numérico em situação de ensino. São Paulo: USP, 1991.

PERRENOUD, P. Práticas pedagógicas, profissão docente e formação: perspectivas sociológicas. Lisboa: Dom Quixote, 1993. 